revista do ieb n 45 p. 63-86 set 2007

\title{
Dialética concretista: o percurso artístico de Waldemar Cordeiro
}

Givaldo Medeiros ${ }^{1}$

Resumo

Análise da trajetória artística de Waldemar Cordeiro (1925-73), desde os anos de formação na Itália até sua morte, através da ruptura abstrata, da radicalização concreta, do devaneio informal, da aproximação participante, da semantização popcreta e da arteônica.

\section{Palavras-chave}

Waldemar Cordeiro, arte concreta, arte abstrata, arte moderna, percurso artístico.

1 Arquiteto (1987) e Doutor (2005) pela Faculdade de Arquitetura e Urbanismo da Universidade de São Paulo. Professor da Universidade de São Paulo (Departamento de Arquitetura e Urbanismo da Escola de Engenharia de São Carlos) desde 1998. 
revista do ieb n 45 p. 63-86 set 2007

\title{
Concrete art and dialectics: Waldemar Cordeiro's artistic route
}

Givaldo Medeiros

\begin{abstract}
This article analyses Waldemar Cordeiro's (1925-73) artistic route, from his formative years in Italy until his death. It does so by the study of the abstract rupture, the concrete radicalization, the informal reverie, the participant approach, the popcreto and the arteônica's semantization.
\end{abstract}

Keywords

Waldemar Cordeiro, concrete art, abstract art, modern art, artistic route. 
Num meio cada vez mais afeito à cordialidade gestada na complacência acrítica do mercado, a figura de Waldemar Cordeiro (Roma, 1925; São Paulo, 1973) permanece referencial. Difícil dissociar obra e personagem, tanto mais para aqueles que vivenciaram o ímpeto renovador que marca sua trajetória na arte brasileira, acelerando, na melhor tradição das vanguardas, o próprio processo e assim o curso da história. Envolto em descrições sempre passionais, repletas de vestígios factuais a enredar uma necessidade aguda de interlocução, decerto incomodava - e muito. Polemista, cosmopolita, contestador, intransigente, agitador, mordaz, agressivo, explosivo, provocador, enérgico, dinâmico, inquieto, criativo, fluente, aglutinador, disciplinado, rigoroso, autoritário, dominador...; a bibliografia sobre Cordeiro é farta em adjetivações, delineando um perfil cuja complexidade, embora densa de história, trai antagonismos e contradições. Passados tantos anos, o homem perdura. 0 vigor da sua presença tem contudo encoberto o conteúdo da ação. Do concretismo à arteônica, via popcreto, sua produção encadeia ópticas supostamente antagônicas, compondo um cenário difuso à primeira vista, cuja variedade ofusca a unidade ética e estética. Com a relativa dispersão do material referente às suas intervenções públicas, as leituras sobre a obra vêm circunscrevendo-a à ilustração das posições que ia assumindo enquanto crítico de arte. Registros em que tem se tornado recorrente considerá-la na alternância do teórico, do artista, do crítico e do divulgador, o que quase sempre mascara, sob essa sucessão de papéis, uma valoração negativa que condena a obra a ser uma mera imagem da teoria.

Não obstante o alardeado dogmatismo, sobressai um processo semeador, de contínua abertura, que procura vivenciar a própria época e conciliar fatura artística e bases teóricas às exigências coetâneas. Percurso em que a obra pictórica adquire a função ímpar de reflexão plástica sobre o panorama artístico, postulando-se como um modo singular e insubstituível de conhecimento da realidade. De modo que pesquisa e experimentação permeiam toda a obra, exigindo que a análise avance além da arte concreta, a qual não seria um fim, mas justamente um tempo de investigação, a predisposição rumo a um novo desdobramento da arte, suspenso com a morte precoce. Se a atuação é emblemática das vanguardas, levada a efeito por meio de choques, impelida pela ruptura, o suceder em fases da produção revela-se uma evidência traiçoeira, devendo ser tomado primordialmente como um deslocamento do campo de interesses, cuja unidade, na perseguição contínua da objetividade e a despeito das divergentes expressões assumidas no trajeto, é 
atestada pela frequência com que se reporta ao próprio passado para situar o presente artístico. 0 núcleo ético e estético situase no momento de maior embate, de franca explicitação de posições, a arte concreta dos anos 1950.

\section{Duplo movimento: arte e país}

Após a Liberazione, Roma tornara-se um pólo de atração para os artistas jovens. Superado o interregno fascista e reatadas as relações culturais com o restante da Europa, operavase uma revisão crítica radical do passado recente. De um lado, em traumática contraposição aos excessos promovidos durante o pesadelo nazi-fascista e portanto avessos ao nacionalismo, perante o qual o universal surgia como fonte de renovação e atualização, grupos progressistas empenhavam-se em levar a produção local para o seio da cena artística contemporânea; de outro, o distanciamento entre a linguagem empregada pelos artistas e a usada pelas camadas populares exigia o reassentamento da arte sobre uma base comum. Alinhados com a arte abstrata, vários artistas aglutinaram-se na tentativa de conciliar comunismo e arte de vanguarda, com o intuito de provocar o livre-pensar dentro do partido.

No convívio com artistas ligados ao PCI, Cordeiro modela suas posições culturais e políticas segundo o conceito de intelectual dirigente de Antonio Gramsci - a partir da premissa de que a atuação cultural é necessariamente política, cabendo ao intelectual, enquanto agente persuasivo, consciente do seu lugar na história, na vida da nação, participar ativamente da produção de valores endereçados à transformação das concepções de mundo das massas. Sua obra segue marcada pela preocupação com a função social do artista, orientada pelo desejo de assentar a arte sobre uma linguagem universal, de modo a restabelecer seus nexos coletivos. Realiza nesse ponto uma interpretação original das idéias de Konrad Fiedler à luz das de Gramsci, reendereçando a pura visualidade ao encontro da vida: a arte é pensada enquanto intelecção da comunicação, como infra-estrutura e meio de pesquisa da linguagem visual.

Apóia-se nas discussões suscitadas principalmente pelo escultor Pietro Consagra e pelo pintor Giulio Turcato, integrantes do grupo Forma, o primeiro grupo abstrato italiano do pós-guerra, entendendo ser essencial orientar o trabalho para a elaboração de uma arte consciente e racional, em franco contraste com o intimismo, o hermetismo e tudo que há de metafísico e transcendente na arte, de modo a valorizar os valores concretos de conteúdo e forma. Além de Consagra e Turcato, o 
grupo Forma reunia Achille Perilli, Antonio Sanfilippo, Carla Accardi, Mino Guerrini, Piero Dorazio e Ugo Attardi. No manifesto Forma I, que acompanhava a pioneira exposição de 1947, autoproclamavam-se "formalistas e marxistas, convencidos de que os termos marxismo e formalismo não são inconciliáveis", sustentando a necessidade de engajamento ético-social, mas identificando a "posição revolucionária e vanguardista" com a rejeição do "realismo conformista" e com o desejo de "levar a arte italiana ao plano da atual linguagem européia"2. Tratavase, afora a tentativa de conciliar suas próprias opções política e estética, sobretudo de uma tomada de posição contra a orientação vigente no PCI, alinhada com o verismo social e impregnada pela malfadada ambição nacionalista. A crítica política ao novecento e sua instrumentalização pelo regime fascista era deixada no ar. É conveniente lembrar o quanto esse modelo programático, em franca explicitação das posturas valorizadas e rechaçadas, definindo o adequado e o inadequado, reflete-se no manifesto Ruptura (ver adiante), apesar das produções artísticas divergirem significativamente.

Como lembra Giulio Argan, no embate que o puro formalismo então estabelece contra o realismo,

não se renuncia ao engajamento ideológico, acentuando-se, pelo contrário, a necessidade de intervir na situação social em fase de transformação; mas sustenta-se que a arte, como todas as demais atividades, deve contribuir para a transformação das estruturas sociais com a sua própria transformação. ${ }^{3}$

0 impasse italiano certifica Cordeiro da incompatibilidade entre regionalismo e arte de vanguarda, postura que será transferida ao meio artístico paulistano, ao enfatizar a primazia do conhecimento, da intelecção, da objetividade e da intencionalidade sobre quaisquer sensibilismos, na polêmica que se seguirá, opondo à visão nacionalista reinante no meio a defesa intransigente de uma arte abstrata de alcance internacional.

Cordeiro desembarca no Brasil no início de 1946. 0 ambiente artístico e cultural, recém-saído da oposição acadêmicos-modernos, dava mostras de saturação do modelo

2 FORMA 1, 1947. In: IMPONENTE, Anna; SILIGAT0, Rosella (Org.). Pietro Consagra. Milano: Mondadori; Roma: De Luca, 1989. p. 194.

3 ARGAN, Giulio Carlo. Arte moderna: do iluminismo aos movimentos contemporâneos. Trad. Denise Bottmann e Federico Carotti. São Paulo: Companhia das Letras, 1992. p. 537. (1º edição de 1988). 
emerso de 1922, avizinhando um idêntico e estagnante risco acadêmico. Durante o Estado Novo, a ambigüidade política de Getúlio Vargas fizera-se sentir também no campo das artes, mobilizando indistintamente acadêmicos e modernos, estes na figuração identitária da nação, que, coerente com a transição vivida pelo país, não poderia deixar de reproduzir uma idéia contraditória e parcial da sociedade, voltada para o que não se conhecia, mas do qual já se afastava. 0 Brasil figurado era duplamente idealizado, beirando a folclorização: o mundo rural distante e desconhecido, tanto quanto já descompassado com a transformação social e física do país - o deslocamento da população do campo para a cidade, real e relativo, denotava a inflexão da estrutura territorial e produtiva, de rural-agrária para urbano-industrial; precedendo em mais de dez anos ao restante do país, a mudança era particularmente sensível em São Paulo.

Na contramão da cruzada anti-racionalista que marca a cultura do segundo pós-guerra e atravessa os anos 1950 sob veste tachista-informal, a defesa de uma arte abstrata e internacional cumpre um papel antitético frente ao nacionalismo defendido pela esquerda. Cordeiro não se filia ao PCB por discordar da orientação partidária predominante, que priorizava o realismo como forma de manifestação artística; questiona as posturas de muitos dos pintores oficiais do partido, avaliadas como deformadoras do próprio realismo social, uma vez que substituíam o registro da luta de classes por uma abordagem populista e naturalista, na qual, segundo ele, os trabalhadores descansam. Prefere, por exemplo, identificar em Alfredo Volpi a habilidade para elevar "o sentimento visual do povo brasileiro à linguagem universal”. Entende que este,

por uma síntese miraculosa do popularesco e do intelecto, de matemática e folclore, desperta a plástica brasileira que descansava ainda nas vetustas descobertas de Almeida Júnior, nas gratuitas variações da emoção cromática e tátil. ${ }^{4}$

Para Cordeiro, Volpi - aclamado pelos artistas concretos como uma comprovação viva da teoria da pura visualidade - seria um dos raros artistas brasileiros a libertar-se da arte narrativa, construindo uma arte de expressão autônoma, singular, mesmo que enraizada no nacional.

4 CORDEIRO, Waldemar. Volpi, o pintor de paredes que traduziu a visualidade popular. Folha da Manhã, São Paulo, 20 abr. 1952. At. e Com., p. 7; CORDEIRO, Waldemar. Volpi, o santeiro cubista. Folha da Manhã, São Paulo, 11 mar. 1951. At. e Com. p. 1, 3. 
Na luta contra o figurativismo, Cordeiro empreende uma defesa radical da arte abstrata. Sustenta que, do impressionismo à nova estética, a essência da arte revela-se na contradição entre "antropomorfismo" e "valores de forma", aspectos negativo e positivo, faces passada e futura, em caducidade e desenvolvimento, de um par dialético que conforma conflituosamente o acúmulo quantitativo que provoca o salto qualitativo. A alusão marxista-hegeliana é explícita: a acumulação quantitativa promovida pela arte moderna cria as condições necessárias para o salto qualitativo contemporâneo ${ }^{5}$. Ruptura que reivindica a "linguagem real das artes plásticas", em conexão com as exigências concretas da sociedade: "conceber a arte como valores de forma sem nenhuma espécie de acréscimos estranhos"; enquanto superação do voluntarismo subjetivista; como modo crítico de conhecimento do passado. Avalia que o naturalismo "fideísta" fracassa por desconhecer o estado atual da arte e não compreender as peculiaridades do seu desenvolvimento histórico, os desdobramentos estruturais inerentes à sua lógica, como transparece localmente na apropriação superficial e maneirista dos procedimentos pós-impressionistas de objetivação da forma e da cor - enquanto repertório, estilo -, destituída do ímpeto revolucionário original, inequivocamente abstrativo, avesso à persistência de qualquer "sensismo" na arte ${ }^{6} .0$ abstracionismo é pensado, por analogia à crítica marxista das ideologias, como um processo de desmonte do olhar instituído, como um instrumento para o desvelamento da opacidade que se antepõe à realidade visual, rumo à construção de uma abordagem que se pretende científica da visão. A arte ambiciona alcançar o estatuto de conhecimento visível, formativo por excelência, sistematizado a partir da investigação da pura visualidade das formas, razão objetiva que funda a nova visualidade moderna.

5 "Dentro da concepção dialética todos os objetos e os fenômenos 'levam sempre implícitas contradições internas, pois todos eles têm seu lado positivo e seu lado negativo, seu passado e seu futuro, seu lado de caducidade e seu lado de desenvolvimento. Do critério que a luta entre estes lados contrapostos, da luta entre o velho e o novo, entre o que agoniza e o que nasce, entre o que caduca e o que se desenvolve, chega-se ao conteúdo interno do processo de desenvolvimento, ao conteúdo interno da transformação das mudanças quantitativas em mudanças qualitativas'." CORDEIRO, Waldemar. Abstracionismo. Artes Plásticas, São Paulo, n. 3, não paginado, jan./fev. 1949. Destaca-se que a citação inclusa, sem identificação da fonte, provém de Materialismo dialético e materialismo histórico (1938), de Josef Stalin.

6 CORDEIRO, Waldemar. Abstracionismo. Artes Plásticas, São Paulo, n. 3, não paginado, jan./fev. 1949. 
Ao postular o significado na arte à margem dos conteúdos verbais, supõe o desenvolvimento de um conhecimento visual colado à especificidade artística, a "possibilidade de uma lógica que não fosse só lógica da filosofia" (em alusão a Giambattista Vico), na qual a "necessidade do homem de construir imagens" investe a arte de uma dimensão concreta frente ao pensamento abstrato da filosofia. Tal especificidade, "faculdade primitiva do homem de criar esse tipo de conhecimento", é amparada por uma citação de Nikolai Bukharin:

0 mundo íntegro das emoções tem também seu ponto de condensação: o pensamento em termos de imagens. Aqui não há abstração do que se sente diretamente. Aqui o processo de generalização não nos leva mais além de seus limites, como ocorre no pensamento lógico e no seu produto mais elevado, o pensamento científico. Aqui esta mesma vida sensorial - duplamente concreta e duplamente 'vivente' - se condensa. Aqui não temos um reflexo científico da existência verdadeira mas um quadro sensorialmente generalizado de uma série fenomenológica, não a 'essência' mas o 'fenômeno'. Aqui o tipo de pensamento não é o mesmo que o pensamento lógico. ${ }^{7}$

Distinção e autonomia entre pensamento por conceitos e por imagens que abre a possibilidade de "pensar a arte como a filosofia da sensibilidade", como imaginação que "cria estruturas formais que permanecem no domínio da sensibilidade", alcançando a "imagem da imagem: princípios de imagens arquetípicas da sensibilidade". A "arte se revela através dos sentidos", no limite estrito do que nos comunica a aparência ${ }^{8}$. 0 artista guia-se pelo que vê.

7 Fragmento veiculado com a I Exposição Nacional de Arte Concreta. BUKHARIN, Nikolai Ivanovich. I Congresso Pan-soviético de Escritores (excerto da conferência Poesia, poética e o problema da poesia na URSS, 1934). AD - Arquitetura e Decoração, São Paulo, n. 20, não paginado, nov./ dez. 1956; e CORDEIRO, Waldemar. Arte concreta. Taquigrafado por Iolanda Frozini. Texto de palestra proferida na Biblioteca Municipal de São Paulo, Serviço de Belas Artes, 4 maio 1961. (Acervo Família Cordeiro). Observase que o excerto não casualmente é extraído do I Congresso Pan-soviético, plataforma de oficialização do realismo socialista, via pronunciamento de Andrei Jdanov na sessão inaugural.

8 CORDEIRO, Waldemar. Arte concreta. Taquigrafado por Iolanda Frozini. Texto de palestra proferida na Biblioteca Municipal de São Paulo, Serviço de Belas Artes, 4 maio 1961. (Acervo Família Cordeiro). 
0 fazer artístico impõe-se como um exercício reflexivo de compreensão e reprodução das conquistas visuais contemporâneas. 0 que emerge dessa reflexão produtiva é uma interpretação original da obra de Piet Mondrian e um conceito básico para a compreensão do concretismo brasileiro: a noção de movimento. Ao invés de aderir ao conceito de planaridade que habita as análises sobre a obra de Mondrian - que engessaria, aliás, muito da produção abstrata posterior -, parte-se da última e inconclusa experiência nova-iorquina dos BoogieWoogies, associando-a à noção de tridimensionalidade óptica, avaliada a obra neoplástica como "movimento de planos colo-

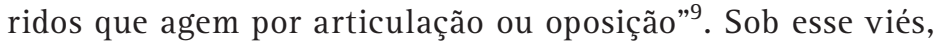
a perdurar durante a saga concretista, busca-se investigar e desvelar a infra-estrutura do visível, pesquisar os mecanismos internos a esse fenômeno para instituí-lo como linguagem, seja em sua efetividade ou falibilidade. Daí advém outro aspectochave para abordar a obra de Cordeiro: a prática é uma análise da paisagem cultural, um debruçamento sobre o outro através dos meios pictóricos; e é com essa experimentação formal peculiar ao fazer artístico, enquanto projeto, realização e consumação, não como manufatura tátil, que chega à superação. Em Movimento (1951) (Fig. 1), o contraste entre as cores complementares visa a condição espacial da imagem, na especulação do processo perceptivo, de como as formas são reconhecidas e organizadas a partir do estímulo fisiológico. Na dissolução do plano neoplástico, a dimensão temporal encontra uma tradução visual, corporificando a noção de movimento, ritmo, mas também virtualidade: opera-se o deslocamento da experiência retiniana do contraste simultâneo para o âmbito da forma, extraindo o espaço da tensão entre imagem e pós-imagem.

\section{Ruptura}

No rastro da I Bienal e da exposição de Max Bill no MASP, em dezembro de 1952, é levada ao MAM (São Paulo) a mostra Ruptura, apresentando as pesquisas sobre arte abstrata que desde 1948 adquiriam corpo no meio artístico paulistano. 0 manifesto lançado na ocasião reivindica visibilidade pública para o concretismo, defendendo uma arte baseada em valores intrínsecos, reflexo das transformações econômico-sociais.

9 CORDEIRO, Waldemar. Arte moderna e naturalismo. Folha da Manhã, São Paulo, 9 dez. 1951. At. e Com., p. 7. 
Explicitando as bases do movimento, essa apresentação da arte concreta é simultaneamente uma ruptura com as instituições e uma ação sobre a cultura. Tratava-se de abrir espaço para o abstracionismo numa dupla frente, contra os interesses extraartísticos que dominavam os julgamentos estéticos, veiculando a discordância com as posições dominantes, e contra a incompreensão do "salto qualitativo" dado pela arte moderna. Impunha-se radicalizar a ruptura para dissociá-la da assimilação naturalista, da neutralização acrítica dos "princípios novos" nas "formas velhas" da figuração, procurando evidenciar e explorar o passo subseqüente, conseqüente à abordagem cubista. Ao redigir o manifesto, Cordeiro quer re-situar a arte perante as transformações que levaram o "naturalismo científico da renascença - o método para representar o mundo exterior (três dimensões) sobre um plano (duas dimensões)" - ao esgotamento da sua "tarefa histórica". À nova época corresponderia uma nova estética e uma nova arte. A decadência da concepção euclidiana do espaço reclamava uma renovação integral dos procedimentos artísticos, orientada por parâmetros objetivos, “acima da opinião", em franca oposição contra a persistência de qualquer naturalismo, seja afirmativo ou reativo - como a arte inconsciente -, e mesmo contra o "não-figurativismo hedonista". Anuncia a crise cuja superação implica necessariamente tanto a "renovação dos valores essenciais da arte visual (espaço-tempo, movimento e matéria)" como o aproveitamento da intuição artística no "desenvolvimento prático", de modo a "conferir à arte um lugar definido no quadro do trabalho espiritual contemporâneo". No verso do manifesto, o compromisso em circunscrever e explorar os valores estruturais da arte denuncia sua base teórica, na alusão a Fiedler: "a obra de arte não contém uma idéia, é ela mesma uma idéia" ${ }^{10}$.

Cordeiro sustenta que

os novos princípios artísticos podem ser resumidos da seguinte forma: construção espacial bidimensional (o plano); atonalismo (as cores primárias e as complementares); movimento linear (fatores de proximidade e semelhança). ${ }^{11}$

10 CORDEIRO, Waldemar; BARROS, Geraldo de; CHAROUX, Lothar; FEJER, Kazmer; HAAR, Leopoldo; SACILOTTO, Luiz; WLADYSLAW, Anatol. Ruptura. São Paulo: Museu de Arte Moderna, 1952. (Manifesto).

11 CORDEIRO, Waldemar. Ruptura. Correio Paulistano, São Paulo, 11 jan. 1953. Suplemento, p. 3. 
À perspectiva cônica e tonal contrapõe o movimento decorrente do acionamento dos valores gestálticos; ao espaço representado renascentista, a radicalização da visão espaçotemporal cubista e a exploração dos aspectos estruturais do quadro. Antítese da visão renascentista que permanece no registro da visão: a obra é feita para o olho, visa a desdomesticação do olhar; o espaço produz-se a partir de efeitos ópticos, renovando a profundidade sobre a planaridade da tela. Em Desenvolvimento ótico da espiral de Arquimedes (1952) (Fig. 2), a geometria - a espiral de Arquimedes encontrando a fita de Moebius - informa a definição do traçado, é o lugar de origem da idéia visivel e a forma do seu desenvolvimento virtual, o desejo de uma nova visibilidade que se dirige a uma barroca tridimensionalidade óptica. 0 movimento não-naturalista é referente ao plano pictórico; a relação centrípeta-centrífuga remete aos ritmos obtidos a partir de formas circulares por Vassili Kandinsky e às construções com linhas de Alexandr Rodtchenko; o traço é o veículo de expressão, gerando o fundo vibrátil sobre o qual paira um signo ${ }^{12}$.

No ápice concretista, durante a I Exposição Nacional de Arte Concreta (1956/57), propõe uma nova correlação entre "0 objeto" e a sensibilidade, fundada na "experiência direta", mas atenta à "potencialidade social da criação formal". Atividade formativa por excelência, limiar e dialética entre pensamento e materialidade, a arte é conceituada como produtora de objetos que são fontes de conhecimento, matrizes de uma nova realidade. Mais do que fatura, a obra é produto; o único conteúdo (e valor) artístico admitido é o fato visual concretamente materializado pela obra. Esse o sentido do apelo ao realismo, à pura visualidade da imagem como salvaguarda do conhecimento acumulado pela arte moderna, na defesa de uma abordagem que se quer adstrita à obra, desvestida de acréscimos estranhos, de projeções heteronômicas. "Realismo artístico e não realismo anedótico." Forma autônoma de conhecimento, a arte afronta o mundo exterior com seus próprios meios, em total independência das injunções verbais, abrindo-se à realidade sem alterar sua essência. 0 aval desse argumento é o conceito de "arte produtiva" de Fiedler, que se opõe ao idealismo da arte de "expressão" - "a arte não é expressão mas produto; a

12 A idéia de espiral-signo é devida a BOHNS, Neiva Maria Fonseca. Idéias visiveis: Waldemar Cordeiro e as razões do concretismo no Brasil. 1996. Dissertação (Mestrado) - Universidade Federal do Rio Grande do Sul, Porto Alegre, 1996. p. 108-9. 
linguagem artística não é expressão do ser, mas forma do ser". Sendo produto, ela não exprime, $\mathrm{e}^{13}$.

0 texto está nitidamente desenvolvido em aforismos. Logo, não é inadequado inferir que a obra artística de Cordeiro segue também uma estratégia aforística, na qual se alternam sucessivas sentenças visuais, idéias visiveis (Fig. 3), que exploram "a natureza sensível da geometria na arte". Para ele, a "arte é geométrica, não geometria", concorde Leonardo Sinisgalli: "a geometria importa até às possibilidades geométricas do nosso olho, não da nossa mente”. Conclui com uma definição de movimento:

A pintura espacial bidimensional alcança o seu apogeu com Malevitch e Mondrian. Agora surge uma nova dimensão: o tempo. Tempo como movimento. A representação transcende o plano, mas não é perspectiva, é movimento. 0 número cromático regula estruturalmente a cor, que age pelo contraste das complementares. 0 interesse pela vibração reflete a aspiração ao movimento. A nossa arte é o barroco da bidimensionalidade. ${ }^{14}$

Idéia que pode ser entendida como ênfase nos efeitos ópticos, mas deve ser tomada sobretudo como pesquisa voltada à desintegração do espaço bidimensional neoplástico através da vibração morfocromática, rumo a uma nova espacialidade.

Reconhecidas a especificidade e a autonomia da arte, credita-se ao fazer artístico um papel analítico, reflexivo, cognitivo, depurador do olhar. 0 fato pictórico adquire significação com a própria prática visual. A arte enquanto "pensamento por imagens" alcança a intelecção artística no ato mesmo em que se realiza. A construção de um campo disciplinar autônomo constitui a essência da arte concreta, informando teoria e ação ao longo dos anos 1950. Alinhando a pura visualidade com o compromisso de fundamentar historicamente a evolução das categorias visuais, a singularidade do concretismo brasileiro e, particularmente, de Cordeiro, deve ser imputada à associação inusitada de Fiedler, Gramsci e teoria da Gestalt: arte como objeto, portanto conhecimento sensível fundado na experiência direta e voltado à pedagogia do olhar, entendidos a ação cul-

13 CORDEIRO, Waldemar. 0 objeto. AD - Arquitetura e Decoração, São Paulo, n. 20, não paginado, nov./dez. 1956.

14 Ibid. 
tural como fato político e o intelectual como agente persuasivo a produzir valores endereçados à transformação das concepções de mundo das massas.

Não obstante a pura visualidade, atinge-se uma nova forma de realismo, fundado na objetivação do processo perceptivo. A arte é concebida como forma de conhecimento; a obra como realidade em si. A atenção volta-se para a estrutura, focada no aspecto relacional mais do que na cor, atenta ao jogo de espelhos entre a planaridade do quadro e a concavidade retiniana. Portanto, a possibilidade de remeter a arte concreta ao impressionismo já está explícita nesse momento. Advém da afinidade com que o impressionismo objetivava a figuração do mundo exterior, ao transferir para a tela a decomposição retiniana do visível, ainda que ora a cor cumpra um papel secundário, defina-se pelo espectro e não mais pelo dado sensível, e seja a forma quem faça as vezes da cor. Impõe-se à forma uma função de dissolução-desenvolvimento simétrica àquela da cor no impressionismo, legando a resolução final da configuração ao plano retiniano. Desse modo, com a persistência da imagem, na exploração da relação entre imagem e pós-imagem, nas vibrações obtidas do desencontro entre tela e retina, obtém-se uma dilatação temporal da percepção. A ambigüidade incorpora o tempo no campo do quadro, estendendo a duração da apreciação do observador; um movimento ocorre.

Dialética e contradição, visão positiva e negativa, evidência e sombra. A idéia de movimento não é só pura objetivação do visivo para a comunicação visual, mas também fissura do óptico. A questão remete ao extremo oposto da "representação mais precisa e eficiente para uma imagem", sobejamente difundida, afeiçoando-se ao impedimento à comunicação imediata. Essa exploração dos paroxismos ópticos diz muito da relação estabelecida com a ciência. Antes de conformar-se à reprodução gráfica ou plástica de procedimentos advindos do conhecimento técnico e teórico da experiência visual, constitui-se uma inquirição artística sobre esse mesmo conhecimento, que por questão de método constrange-se ao domínio visual; o recurso à Gestalt não comparece só como forma de estruturação do quadro, mas também como forma de instabilização. Há portanto na prática concretista um claro apreço pelo desvio, na sombra do apreço pela razão, quando o princípio de proximidade e semelhança concorre para a multiplicação, por ambivalência e ambigüidade, do tema central. Implicando construção sobre o plano e fenômeno perceptivo, a obra adere ao estímulo, suspende-se (instabiliza-se) a comunicação, tensiona-se a visão natural, equiparados figura e fundo. A ambigüidade espacial é movimento virtualmente gerado por 
efeitos ópticos, ilusão de profundidade sem o apelo à perspectiva. Nessa ambivalência entre o plano bidimensional e a imagem tridimensional, o concretismo institui-se como uma desconstrução avant la lettre do olhar.

\section{Persistências em deslocamento}

Em 1961, Cordeiro situa a arte concreta a partir das contradições que caracterizavam a arte contemporânea e levanta a hipótese de uma história da arte livre do comprometimento com o modo de evolução técnico-científico, em vista dos evidentes conflitos entre racionalidade técnica e desenvolvimento social. A arte concreta é apresentada como uma via para se solucionar o conflito moderno entre a concepção de arte autônoma e a consciência dos problemas históricos da cultura. Balanço do passado que lança olhos ao futuro, essa perspectivação histórica da arte concreta alinhava-a com questões que contemporaneamente punham em risco valores fundamentais da arte moderna. Na subjetividade simbólica da cor tachista, Cordeiro identificara a persistência, sob outra forma, da contradição inicial entre pintura figurativa e pintura não-figurativa - arte como expressão versus arte como conhecimento. Tanto quanto a pintura metafísica atribuía à forma um valor simbólico, convencional, acreditava na possibilidade da cor assumir um conteúdo substantivo ou adjetivo, sígnico ou simbólico. 0 dilema tachista irá catalisar esse deslocamento da reflexão concreta da forma à cor, delineando o desafio de considerá-la objetivamente. A "arte concreta informal", conforme Cordeiro a nomeia, "reivindica para si o conteúdo positivo do impressionismo" - o problema objetivo da fusão óptica das cores, de caráter estrutural, que se explicita no pós-impressionismo:

0 neo-impressionismo permite que seja feita uma mescla através do olho do espectador; não mistura tintas, mas mistura sensações; evidentemente, no momento em que se misturam sensações de cores, cria-se o problema do equilíbrio; harmonia e equilíbrio se relacionam à superfície e à intensidade da cor. ${ }^{15}$

A origem dessas considerações estão uma vez mais filtradas pela abordagem cubista, agora na sua vertente informal,

15 CORDEIRO, Waldemar. Arte concreta. Taquigrafado por Iolanda Frozini. Texto de palestra proferida na Biblioteca Municipal de São Paulo, Serviço de Belas Artes, 4 maio 1961. (Acervo Família Cordeiro). 
o cubismo órfico de Robert Delaunay e seus contrastes simultâneos, produzidos a partir da teoria de Michel-Eugène Chevreul. Em prosseguimento à pesquisa anterior e em atenção ao apelo contemporâneo à participação, lança-se a arte concreta contra o seu negativo, na tentativa de se alcançar uma nova síntese, saída da imbricação dos contrários. No enfrentamento do informal, retém-se a noção de estrutura, a despeito da neutralização do contorno geométrico, atenuado entre manchas cromáticas difusas, em cores primárias e secundárias, pulverizadas mecanicamente sobre a tela com o auxílio de um compressor (Fig. 4). Se antes o concurso dos elementos geométricos era o fator precipitador do espaço, agora são as cores que desempenham esse papel. Do acento formal ao acento cromático, da dissolução da cor pela forma à dissolução desta pela cor, caminha-se da tridimensionalidade óptica para a evidência planar da noção de forma como relação. Sem contorno, sem invólucro, face negativa do concretismo geométrico, a fase cor-luz é dialeticamente seu par complementar. A participação inscreve-se no domínio mesmo do óptico, ou antes, toma-se consciência e associa-se o fato retiniano com o papel ativo do fruidor. A despeito da interpretação comumente atribuída aos trabalhos dessa fase, considera-se que eles se mantêm no domínio estrito da razão, representando uma extensão do desenvolvimento anterior. Na transcendência da forma, retida no limite da desaparição, a objetividade fixa-se na problematização da cor; a persistência retiniana da imagem luminosa é ainda o fundamento fisiológico que ancora a unidade estrutural. Desfocada a forma, a configuração resiste, sustentada pelo acordo entre forma e cor - com o acento deslizando de uma para a outra -, sublinhado pelo contraste das complementares; a espacialidade óptica e o movimento transferem-se para a vibração cromática, gerando um espaço virtual com a interpenetração das formas. A construção pela cor. A aspersão controlada do jato de tinta, entre a determinação e o acaso, a um tempo dissolve de fato o contorno e o retém como um limite virtual, ensejando uma diferenciação de planos sem superposições: o tonalismo comparece paradoxalmente para a definição de margens internas. A profundidade espacial nasce não da diferença de tom, mas da identificação dos matizes: as manchas configuram campos cromáticos mais e menos homogêneos, pulsantes ou retráteis, discerníveis no interior do véu de luz e cor como regiões probabilísticas, que persistem no limiar da indeterminação, retidas entre o desvio padrão. 
0 impasse informal acentua-se, num reencontro e adeus ao pincel, exposto na individual da Galeria Astréia (1963). As obras mostram uma mobilidade ainda apegada ao cubismo, análoga à percorrida pelos protagonistas, a do deslocamento de uma fase analítica para uma fase sintética: a arte concreta informal encontra os papiers collés cubistas (Fig. 5). Cordeiro busca uma saída ainda no interior do concretismo, uma forma final de afirmação do seu conteúdo radical, que só pode se consumar como explosão. A objetividade deixa de associar-se à forma ou à cor para tornar-se puramente relacional, realizando a flexibilização da arte concreta no mesmo ato em que reafirma seus pressupostos primordiais - o debater do pincel na tela é ritmo; o fundamento da imagem é a relação. Embaralhadas as formas e as cores, a arte concreta afronta diretamente a mancha, o gesto, o papel, o algodão, o esparadrapo, para evidenciar uma vez mais a subestrutura da obra, o seu caráter relacional, a sua possível recuperação pelo fruidor a partir dos fatores de proximidade e semelhança, uma configuração (Gestalt) anuncia-se na floresta tachista. Difícil rastrear a sequência cronológica com que se produzem tais pinturas, dado seu caráter compulsivo, mas independente de qualquer arranjo temporal, dessa catábase informal emerge uma revisão mais radical da arte concreta, aprofundando o antes entrevisto com a fase cor-luz. A forma decanta-se no substrato estrutural, a luz refratada reencontra a viscosidade da tinta. Dos campos cromáticos da cor-luz à floresta tachista, a indiferenciação gestáltica ronda as telas, o curso tátil e diletante do pincel detémse apenas na persistência serial, pedra de roseta invertida, construída para se decifrar. Nem contorno nem cor, a forma revela-se como infra-estrutura da linguagem.

Momento de inflexão, de superação do impasse concretista - então desarmado de seu poder de choque -, de revisão e reelaboração das bases teóricas, reencontrando-se paradoxalmente na sempre evitada fatura da tela, na experiência do fazer. Nessa aventura com pincéis, Cordeiro demonstra uma enorme disponibilidade para afrontar o fato artístico desarmado de quase todos os pressupostos anteriores. Afasta-se da forma rígida, o trabalho é essencialmente especulativo, a tela é de novo por um momento um laboratório para o estudo da visão. A elaboração processa-se com os próprios meios da pintura, numa quantidade imensa de estudos - só comparável a outro ponto de inflexão decisivo na sua carreira, quando voltou-se à obra de Mondrian -, num encontro com o empírico, lançada dialeticamente a arte concreta contra a arte informal. Nessa conjunção dos pressupostos concretistas primordiais com os do seu contrário, uma metamorfose começa a processar-se. Espelham-se e identificam-se os resíduos de objeti- 
vidade no interior da subjetividade tachista; descobrem-se alguns fundamentos construtivos no automatismo informal; às noções de ritmo e relação agregam-se as de acaso e materialidade, que serão incorporadas como fatos artísticos na obra subsequente. 0 quanto sua arte persistirá nesse empenho serial só a fase popcreta de fato dirá. Mas a passagem da arte concreta à popcreta, da tese à antítese, da imagem pura à coisa crua, depende justamente desse entreato informal. Trata-se de uma despedida da pintura rumo ao objeto. 0 momento decisivo em que ocorre a passagem da imagem para a materialidade. 0 desafio informal conduz à nova figuração, preparando o terreno em que a realidade se cristalizará, deitandose sobre a contextura concretista. A mediação final viria com a arte pragmática, adentradas de vez as vias artísticas do aleatório e do papel ativo do espectador.

Rechaçada a tentação figural, Cordeiro retoma a idéia que se insinuava à época da inflexão cor-luz, deslocando a ênfase que no período concreto histórico recaía no eixo "sintático" para o aspecto "pragmático" da linguagem. Na apresentação do catálogo da exposição Novas Tendências - última tentativa de reagrupamento dos artistas concretos, já com uma roupagem mais inclusiva e menos ortodoxa, não obstante comprometida com as tendências de vanguarda -, afirma que o impacto provocado pela arte informal determinara o fim de todos os purismos acadêmicos, no

apelo para um 'retorno às coisas' ou, se preferirem, à matéria, e à mancha que significa ambigüidade, indefinido, possibilidades de escolha e de direções de leitura, movimento, instabilidade e aleatório. $^{16}$

A transformação do ambiente artístico requeria adequação equivalente da arte concreta, reforçando sua natureza comunicativa, seu caráter eminentemente relacional, redirecionando sua vocação construtiva, na superação do objeto, rumo à aproximação participante - que no entanto mantém-se colada a uma abordagem objetiva, apoiando-se na teoria da informação. Ambiguidade (1963), Opera aperta (1963), “objeto não-unívoco, que usa signos não-unívocos ligados por relações não-unívocas”, diminuindo “o provável (significado) em favor

16 CORDEIR0, Waldemar. Coletiva inaugural 1. São Paulo: Associação de Artes Visuais Novas Tendências, Galeria NT, 9 dez. 1963. Não paginado. Catálogo de exposição. 
do improvável (informação). Não o controle do aleatório, mas a surpresa, a desordem e a imprevisibilidade do aleatório."

Associado o significado com o conteúdo e a informação com as estruturas formais novas, procura-se acentuar o improvável para aumentar a informação. A crítica dos fatores heteronômicos à arte dirige-se à previsibilidade do significado e, inversamente, ao perseguir uma arte de informação - "produto (Fiedler), não expressão de uma problemática, mas ser realidade somente no instante em que aparece e não por força de antecedentes e heteronomismos" -, busca sustentação nas "metáforas epistemológicas (Umberto Eco) dos artistas”. Arte de combate.

Demolir o significado é demolir o sistema. É a desordem ou, como escreve Umberto Eco, um tipo de não ordem habitual e previsivel. Uma racionalidade da desordem, se não for um paradoxo, que no plano social, quiçá, devolva ao indivíduo algo do muito que lhe usurparam. ${ }^{17}$

0 ímpeto informal paralisa-se, o gesto-névoa dissipa-se, persiste o serial como matéria incrustada diretamente no campo pictórico. Os elementos anteriormente apostos (algodão, papel colado) adquirem relevo, o fundo neutraliza-se. A Gestalt reconfigura-se, emerso o artista do excesso de gestos, tintas e pincéis. A afluência de figuras-traços é progressivamente dissolvida, descoberta uma nova possibilidade de significação. 0 artista reencontra-se enquanto assenta-se na tela o excurso tachista. Figura e fundo separam-se, proximidade e semelhança destacamse no fundo congelado - um monocromo. 0 gesto é absorvido pelo matiz único do fundo, o procedimento serial objetualiza-se nas duas telas apresentadas na VII Bienal de São Paulo (1963), que sintetizam a experiência: a Ambiguidade estrutural concretista afirma-se agora como Opera aperta (Fig. 6 e 7). Do máximo ao mínimo de entropia, da floresta de gestos ao deserto monocromático, é a arte que se dobra sobre si mesma, realizando pictoricamente uma síntese da cena artística contemporânea - o gesto-rasgo incisivo à Lucio Fontana, o procedimento matéricoserial à Enrico Castellani sobre o monocromo azul de Yves Klein e o acromo de Piero Manzoni abrem espaço para a emergência na tela da Nova Tendência do GRAV (Groupe de Recherche d'Art Visuel), Julio Le Parc à frente; a teoria da informação deita-se sobre o grau zero da pintura. Com a incrustação da Nova Tendência

17 CORDEIR0, Waldemar. Coletiva inaugural 1. São Paulo: Associação de Artes Visuais Novas Tendências, Galeria NT, 9 dez. 1963. Não paginado. Catálogo de exposição. 
na tela, por meio de espelhos, o núcleo sintático concretista, depurado paradoxalmente pela digressão informal, encontra seu desdobramento natural, da fisiologia da visão rumo à pragmática, à dimensão participante, vinculando a pesquisa comunicativa teórica à fruição direta do espectador. A compreensão do fenômeno visual passa a ser receptiva à condição em que este ocorre, ao papel voluntário ou involuntário desempenhado pelo sujeito da percepção; a obra incorpora a própria impossibilidade de predeterminação total dessas condições; o real não é representado, mas inserido diretamente na tela, antecipando o desdobramento popcreto. A orientação participante, circunscrita ao domínio pragmático da comunicação, logo assumirá feições semânticas. Cordeiro vai explorar esses vínculos com a nova figuração.

Montagens com sobras da sociedade de consumo, móveis secionados obliquamente, pintados com tintas industriais vivas e puras, rodas de bicicleta, calotas de automóveis, ferramentas de trabalho manual marcam o retorno ao real, a investigação de novas estruturas significantes. Para ele, com a nova figuração, o conhecimento sobre a comunicação visual atinge um novo patamar:

A arte moderna, depois de um período sintático (relação formal entre signos) e de um período - mais recente - pragmático (relação dos signos com o intérprete), inaugura um período semântico (relação do signo com as coisas). ${ }^{18}$

A realidade ordinária torna-se objeto. Com a montagem sobre a tela de elementos tomados da "paisagem criada pela técnica do homem moderno", almeja um "realismo brutal", reinvestir as coisas de significação, expor o embrutecimento da existência pelos meios de comunicação na sociedade de massa. Vertida a arte sobre si, a nova figuração ou "arte concreta intencionante" marca o fim de um processo.

E será a arte concreta intencionante, ou a NF, que dará o golpe mortal no seu adversário, o figurativismo, atingindo-o no coração que nada mais é do que o significado referencial. Nas obras não haverá mais métodos e processos formais para a representação de coisas, e sim as próprias coisas. E se um sig-

18 CORDEIRO, Waldemar. VII Bienal - Nova Figuração denuncia a alienação do indivíduo. Brasil Urgente, São Paulo, n. 40, p. 15-21, dez. 1963. 
nificado referencial deverá permanecer, este partirá das coisas para as representações. ${ }^{19}$

Assumido o fruidor como sujeito da percepção, os aspectos semânticos adquirem importância progressiva, a NT contagia-se com a NF. "A problemática atual propõe uma NF concreta, em termos semânticos, pois a arte concreta não é um dogma, mas um método". Ainda que ombreando a contingência, o particular, não se quer porém "o retorno a métodos anacrônicos próprios do figurativismo e das figurações”, ansiando-se inversamente pela definição das bases de um "novo-construtivismo”, em contraposição simultânea à arte concreta histórica, por circunscrita ao aspecto comportamental, e às tendências realistas voltadas à crítica social, por misoneístas.

A arte concreta histórica se fundamentava na percepção (Gestalt). A NF se realiza na apreensão. Sartre explica que apreender não é perceber, mas multiplicar sobre o objeto todos os pontos de vista possíveis. ${ }^{20}$

Sob a lógica sartreana, as coisas introduzidas na tela são refratadas, explodidas em múltiplas configurações. 0 artista propõe "destruir os códigos. Como a arte concreta desarmou a arte abstrata, o construtivismo semântico desarma o figurativismo.” Explicitam-se os vínculos entre a multiplicação das imagens na sociedade de massa e a paralisia da imaginação, impondo uma nova pauta para a arte.

É o momento de ir para a realidade e operar no seu seio. Reconstruir a realidade que, depois do afastamento da arte criativa, ficou entregue à banalidade e à decadência derradeira de formas anacrônicas. É o momento de se aproximar de um público maior, operar nas esferas da realidade que não conheceram a arte pura a não ser em formas degeneradas e consumidas. ${ }^{21}$

Inflexão que gera nova inflexão, no compromisso com a objetividade na arte, na visão sempre positiva do fato artístico. Reiterem-se as diferenças:

19 CORDEIRO, Waldemar. Novas tendências e nova figuração. Habitat, São Paulo, n. 77, p. 56, maio/jun. 1964.

20 CORDEIRO, Waldemar. Problemática da arte contemporânea. São Paulo, 23 jun. 1964. Datilografado. Acervo Família Cordeiro.

21 Ibid. 
Arte concreta é linguagem de natureza objetivo-condutal; arte concreta histórica é sintaxe (métodos racionais de representação); novas tendências (européias) é pragmática (apresentação de possibilidades condutais de materiais e processos da técnica industrial). ${ }^{22}$

Ambas atuam no âmbito das infra-estruturas econômica e visual, nas quais "tudo é higiênico, impessoal e econômico. 0 fruidor não passa de uma retina virgem e desinteressada”. Com o fim da utopia de redenção social via revolução tecnológica, a instrumentalização da arte pela lógica produtiva industrial e a coisificação dos sentidos, inverte-se o reduto do naturalismo, agora acomodado no seio das novas tendências européias, pois estas mantêm a relação entre fruidor e obra no plano puramente óptico, fisiológico. Tudo consumido - deglutição pop do real -, Contra os urubus da arte concreta histórica e Contra o naturalismo fisiológico op (Fig. 8) são títulos de obras do período, a proclamar a inatualidade da pesquisa sintática e pragmática, assimilando a crítica neoconcreta à Gestalt, embora com outro viés. Para Cordeiro,

[...] o problema é deslocar a arte objetivo-condutal da infra-estrutura para a superestrutura, passando da esfera da produção para a esfera do consumo. Deslocar a pesquisa do estudo racional do comportamento diante de fenômenos ópticos para o do comportamento diante de fatos visíveis carregados de intencionalidade e significação dentro de contextos histórico-sociais. ${ }^{23}$

E conclui: "não basta pesquisar, a realidade exige opções combativas" 24 . Com o popcreto, chega a novo salto qualitativo na arte, deslocando a pesquisa infra-estrutural para a construção-desconstrução semântica, para a imbricação da figura no espaço concreto. Diferentemente da pop art, não é a ironia que é realçada, mas a disjunção das referências na sociedade de massa.

A dimensão semiológica, o envolvimento com a teoria da informação conduzem o artista a uma nova abordagem

22 CORDEIRO, Waldemar. Arte concreta semântica. São Paulo: Galeria Atrium, dez. 1964. Não paginado. Catálogo de exposição.

23 Ibid.

24 Ibid. 
programática, a arteônica, através da qual começa a afastar-se de fato da arte concreta (arte dialética de base cubista), mas não sem mantê-la ainda como referencial crítico. A infra-estrutura concreta alcança o estatuto de algoritmo; a imagem é tratada como dígito; a idéia de razão matricial, programada por computador, assume contornos técnicos. A máquina é pensada a serviço da ampliação do acesso das massas à arte, o fazer é adequado às características estruturais do veículo, o artista investiga a expressão condizente com o meio. Bits e bytes como cerne estrutural, caracteres, pontos matriciais e linhas plotadas como elementos superficiais compõem o novo vocabulário, nas pioneiras experiências com computador aplicado à arte na América Latina (Fig. 9). Ressalta-se que a atividade produtiva é sumamente técnica, envolve o encadeamento racional das tarefas e o concurso coletivo dos saberes; que o artista elabora um projeto a ser veiculado - e não mais executado - segundo bases previamente estabelecidas.

Nesse renovado encontro com a tecnologia, pautado pela pesquisa dos fundamentos da visualidade, entrevia-se a possibilidade de compilação objetiva (digital) dos elementos característicos de uma obra, permitindo a análise precisa da linguagem do artista, seus procedimentos lógicos, sua evolução temporal; advogava-se a teletransmissão da obra, ampliando seu raio de ação. Cordeiro reputava a arte computadorizada como a única alternativa justificável para o mundo mecanizado criado pela revolução industrial. Acreditava que os velhos canais de comunicação haviam se tornado obsoletos com a sincronização da emissão e recepção da informação, com a emergência da massa como ator urbano. Pensando a arte sob ampla audiência, livre das condicionantes físicas e semânticas, apreensível diretamente e não por meio de reproduções, a obra desmaterializa-se, cindida pelo canal de transmissão entre os pares fonte e imagem. Concepção (elaboração do programa de computador) e realização (veiculação digital) são dissociados radicalmente, garantindo uma produção mais rápida e precisa da obra, automatizada, bem como a multiplicação da sua recepção, sem ruídos de transcodificação.

Os deslocamentos na produção artística de Cordeiro são indícios igualmente significativos dos seus interesses e objetivos permanentes, do reposicionamento crítico que acompanha cada movimento. 0 afastamento da arte concreta ocorre portanto para melhor realizá-la, introjetada a objetividade na infra-estrutura da imagem. Para ele,

A arte computadorizada, enquanto metodologia, se identifica, em última análise, com as tendências da arte contemporânea 
chamadas, genericamente 'construtivas' e que visam à quantificação e à digitalização dos elementos da obra de arte. ${ }^{25}$

Expressão da evolução tecnológica e da explosão urbana, da redução das distâncias provocada pelo desenvolvimento das telecomunicações, a arte digital teria a arte concreta como precursora, irmanadas na busca de uma sintaxe coerente com a sociedade industrial, no desejo de estabelecimento de uma cultura artística de alcance nacional e internacional, separadas entretanto pelo impacto avassalador da cultura de massa - pelo intervalo popcreto de reelaboração semântica dos dilemas da sociedade de consumo.

Construir e destruir. Destruir para construir, essa é a essência da obra artística de Cordeiro. A desintegração da imagem é constante. No início abstracionista, a imbricação lírico-cubista; logo depois, às voltas com a deglutição pictórica de Mondrian, em busca da Estrutura plástica (1949) da visualidade, interlúdio de tensionamento progressivo da bidimensionalidade, rumo à tridimensionalidade óptica de Movimento (1951) e Desenvolvimento ótico da espiral de Arquimedes (1952) (Fig. 1 e 2). Ruptura visual que caminha para o ápice concretista com a série de Idéias visíveis (1955-7) (Fig. 3); explora a ambigüidade estrutural, instabilizando a relação entre figura e fundo, mediante a dissolução do plano pela forma, depois desta pela cor - na fase cor-luz (Fig. 4) e na vertigem concreto-informal que a sucede (Fig. 5) -, para tornar a forma mais evidente, antes livre de contornos, doravante já implícita como subestrutura, núcleo sintático de uma pulsão participante. Ambiguidade (1963), Opera aperta (1963, a tela rompe-se em espelhos-reflexos-miragens que devolvem-inscrevem o olhar fruidor) (Fig. 6 e 7). Ela própria neutraliza-se, paralisa-se, condensase como superfície sólida, um quase-objeto, receptiva a ele - um monocromo rasgado, deflorado. 0 semântico conquista a tela, acamando-se no leito concretista. Explode em símbolos, ícones, sinais, nas coisas mesmas. A voragem pop, a cultura de massa, a ditadura militar encontram par no desmonte cubista do cotidiano, na denúncia bricoleur do banal, expondo a fis-

25 CORDEIRO, Waldemar. Computer plotter art. São Paulo: Mini Galeria da Biblioteca do USIS, Serviço de Divulgação e Relações Culturais dos EUA, 1731 mar. 1970. Não paginado. Catálogo de exposição. 
sura da sociedade industrial. Assim os popcretos inscrevem a imaginária pop; a arte deita-se à realidade (Fig. 8). Indivíduo e massa, fotografias e objetos, cinéticos e eletromecânicos, cortados, cindidos, pautados, $O$ beijo (1967) - antimáquina orgástica em andywarholiano beijo à Jean Tinguely. A seqüência incorpora a teoria da informação, uma vez mais como ruído, ao sabor do acaso, binária, sim-não (Fig. 9). Em Cordeiro, a arte revela-se sobretudo como inquietação, questionamento, desconstrução. A difícil opção de conciliar visão crítica e visão construtiva da sociedade define o caráter eminentemente experimental, especulativo, analítico, da sua produção artística. Construção em vias de dissolução, toda razão, mas aventurosa, num romântico afrontamento da objetividade. A arte como processo formativo, metaformal, indutor de formas, modos e métodos particulares - esquemas, modelos reduzidos, maquetes, mônadas, partes totais, formas livres em busca de uma aderência à vida -, realiza nesse impasse seu trajeto de vanguarda. 
Figura 1: Movimento, 1951

têmpera sobre tela, $90.2 \times 95 \mathrm{~cm}$

MAC-USP

Foto: Acervo Família Cordeiro

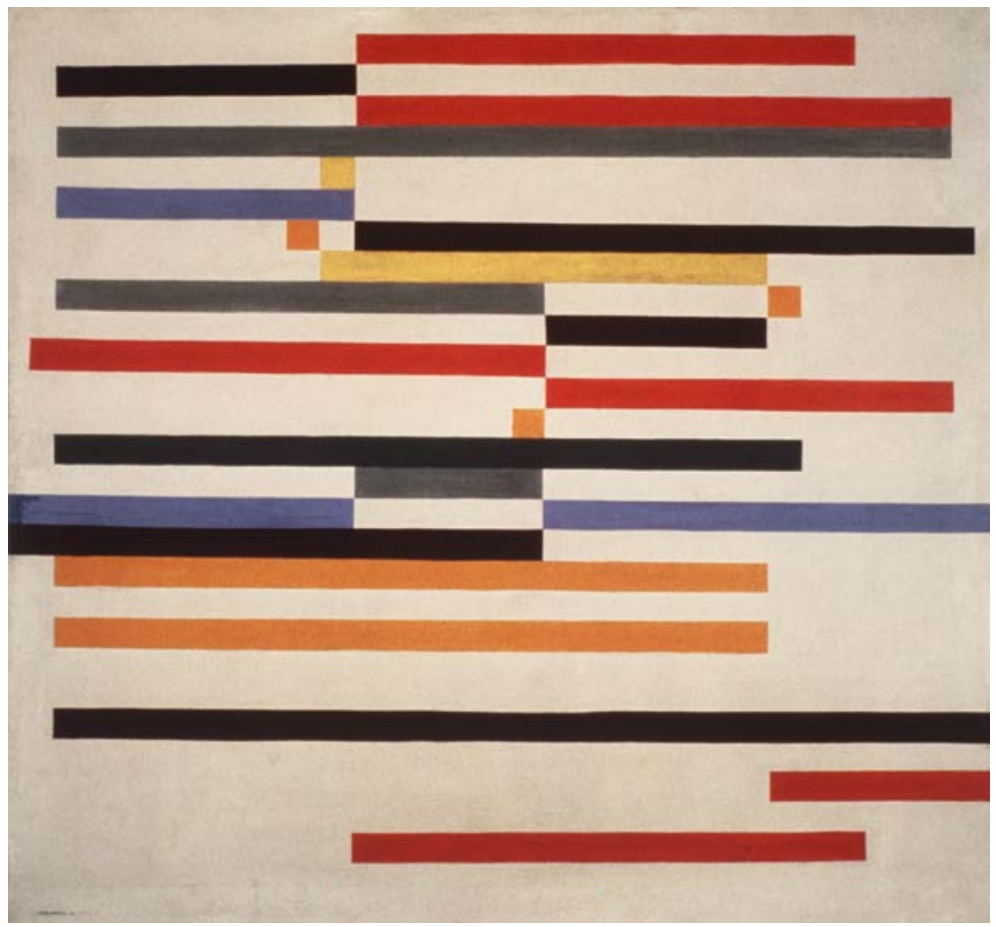


Figura 2: Desenvolvimento ótico da espiral de Arquimedes, 1952 esmalte sobre aglomerado de madeira, 71 x $60.5 \mathrm{~cm}$

Acervo Família Cordeiro

Foto: Acervo Família Cordeiro

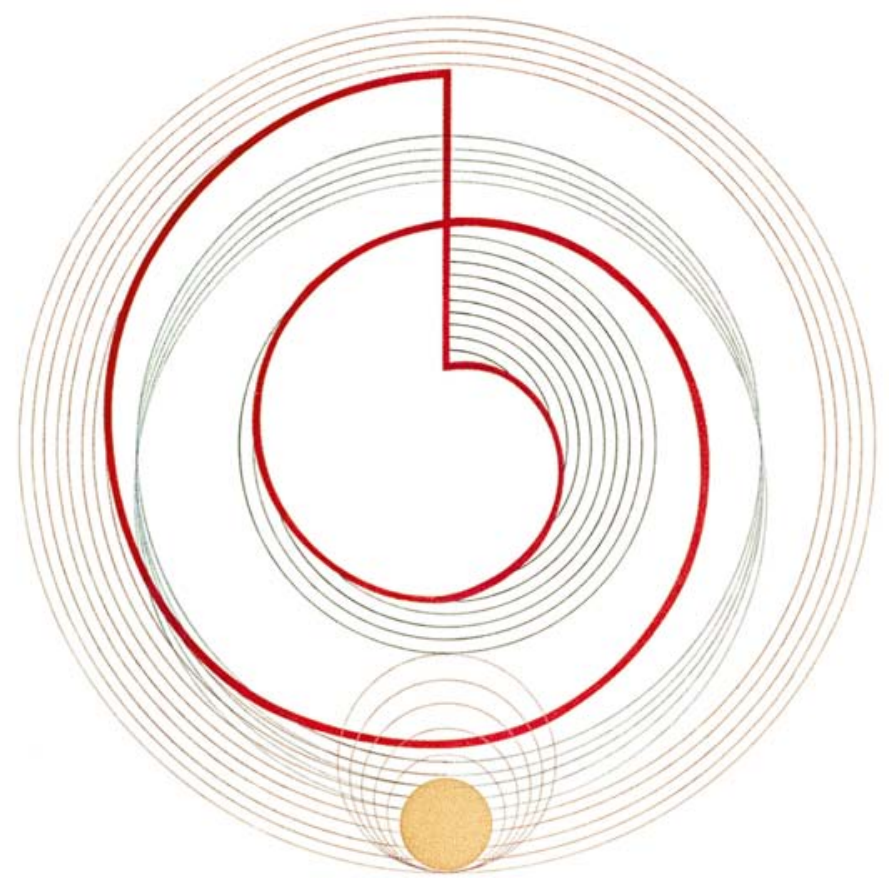


Figura 3: Idéia visível, 1956

tinta em massa sobre aglomerado de madeira, 50 x $50 \mathrm{~cm}$ Acervo Família Cordeiro

Foto: Acervo Família Cordeiro

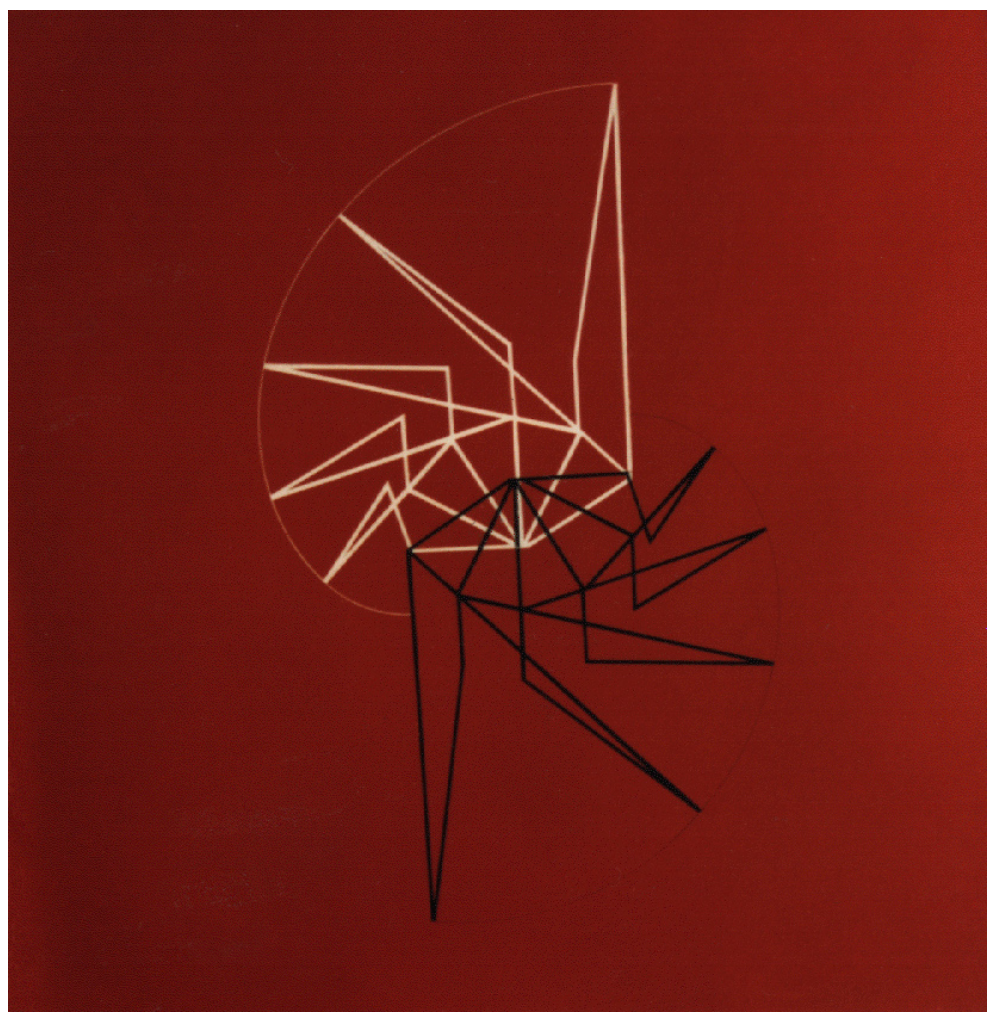


Figura 4: Cor-relação, 1961 óleo sobre tela, $75 \times 75 \mathrm{~cm}$

Acervo Família Cordeiro

Foto: Acervo Família Cordeiro

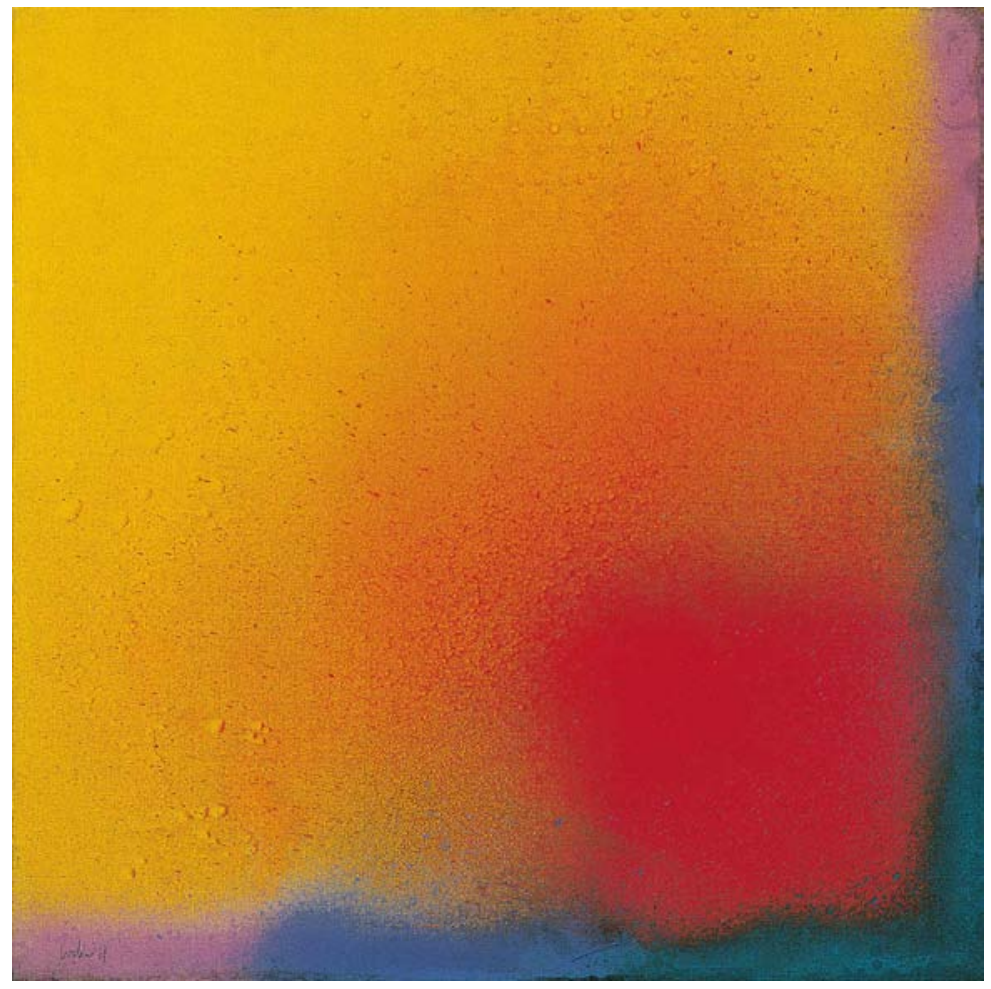


Figura 5: Sem título, 1963

óleo e algodão sobre tela, $75 \times 75 \mathrm{~cm}$

Coleção particular

Foto: Acervo Família Cordeiro

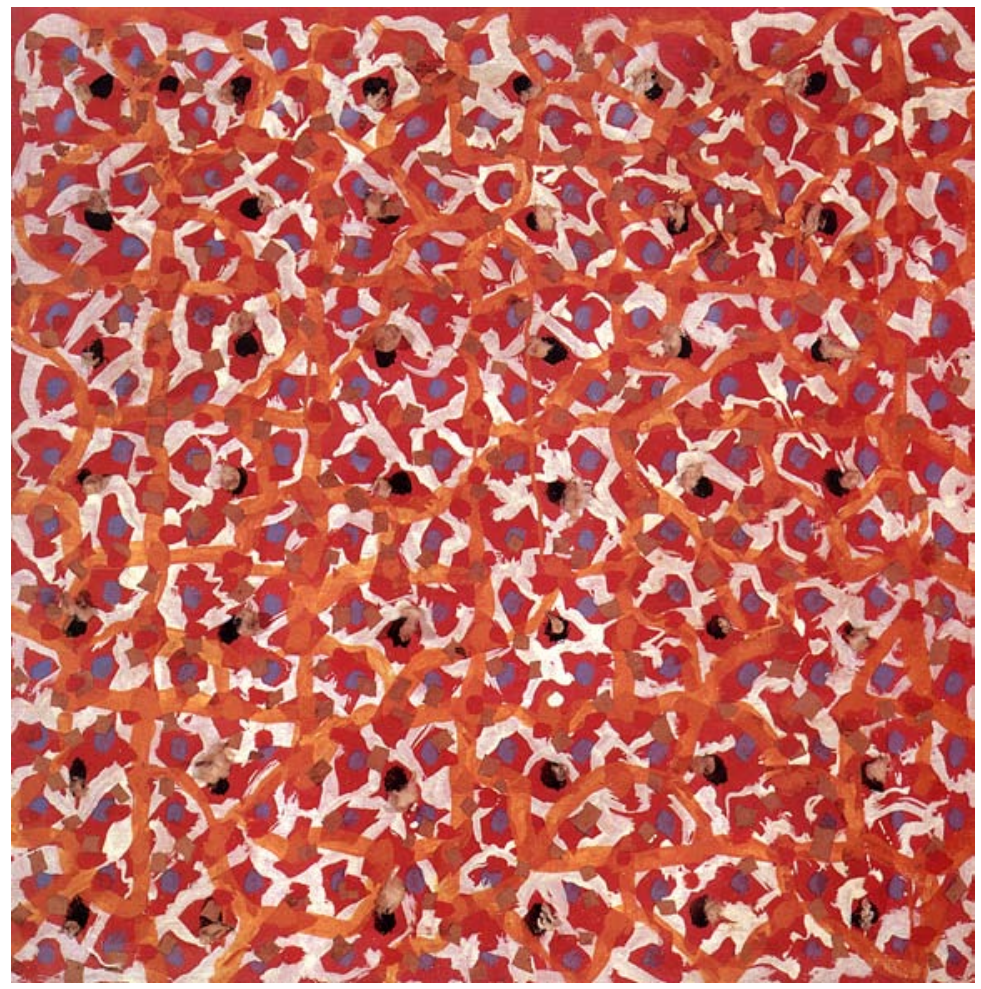


Figura 6: Ambiguidade, 1963

tinta alumínio e espelhos sobre tela, $69 \times 156 \mathrm{~cm}$

Acervo Família Cordeiro

Foto: Acervo Família Cordeiro

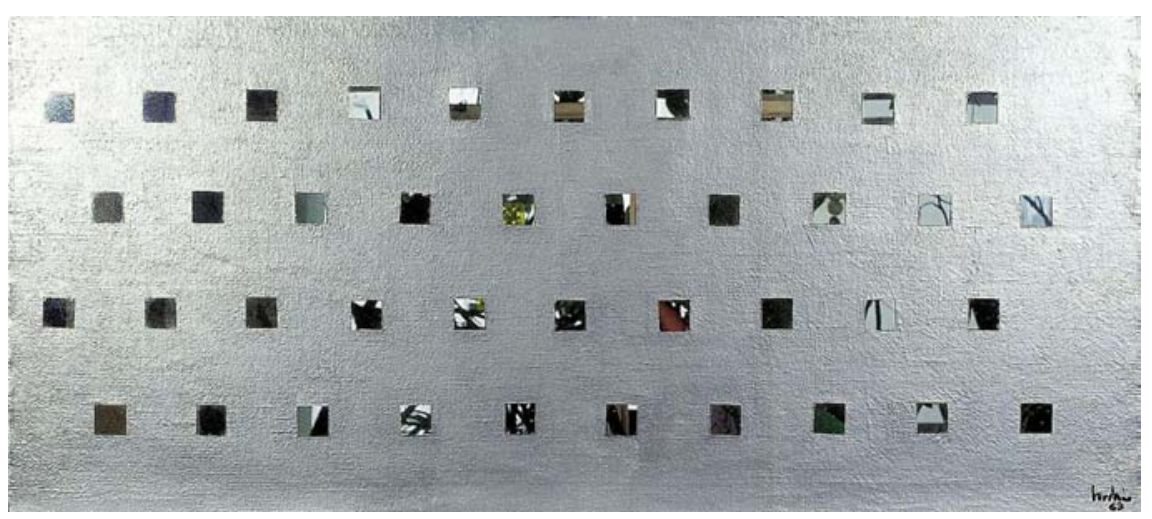

Figura 7: Opera aperta, 1963

óleo, espelhos e papel sobre tela,

$75 \times 150 \mathrm{~cm}$

Acervo Família Cordeiro

Foto: Acervo Família Cordeiro

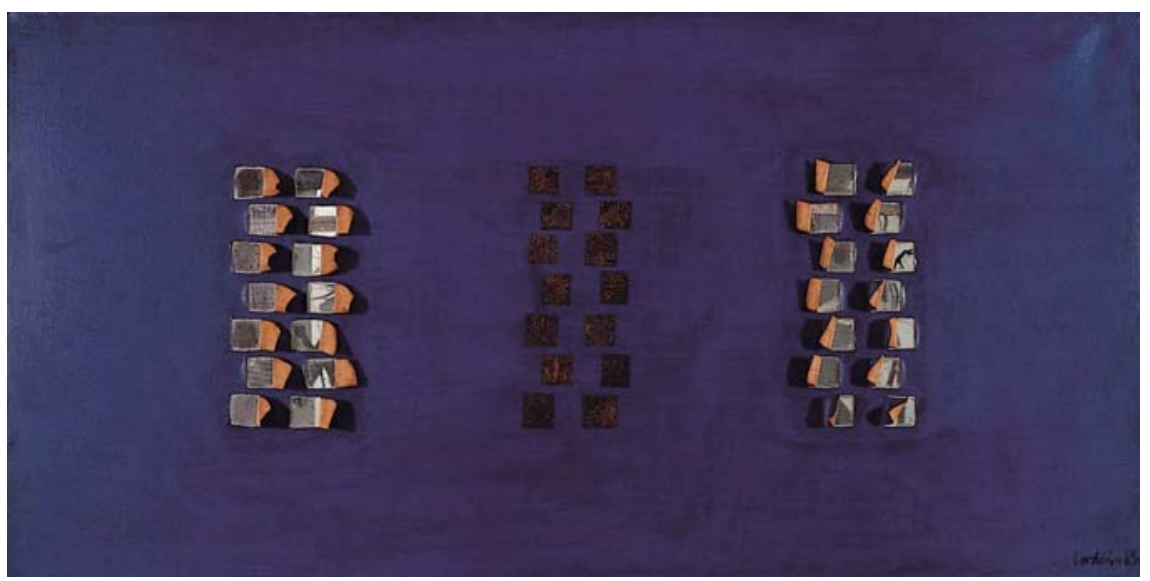


Figura 8: Contra o naturalismo fisiológico op, 1965 montagem com rodas de bicicleta, $110 \times 150 \mathrm{~cm}$

Acervo Família Cordeiro

Foto: Acervo Família Cordeiro

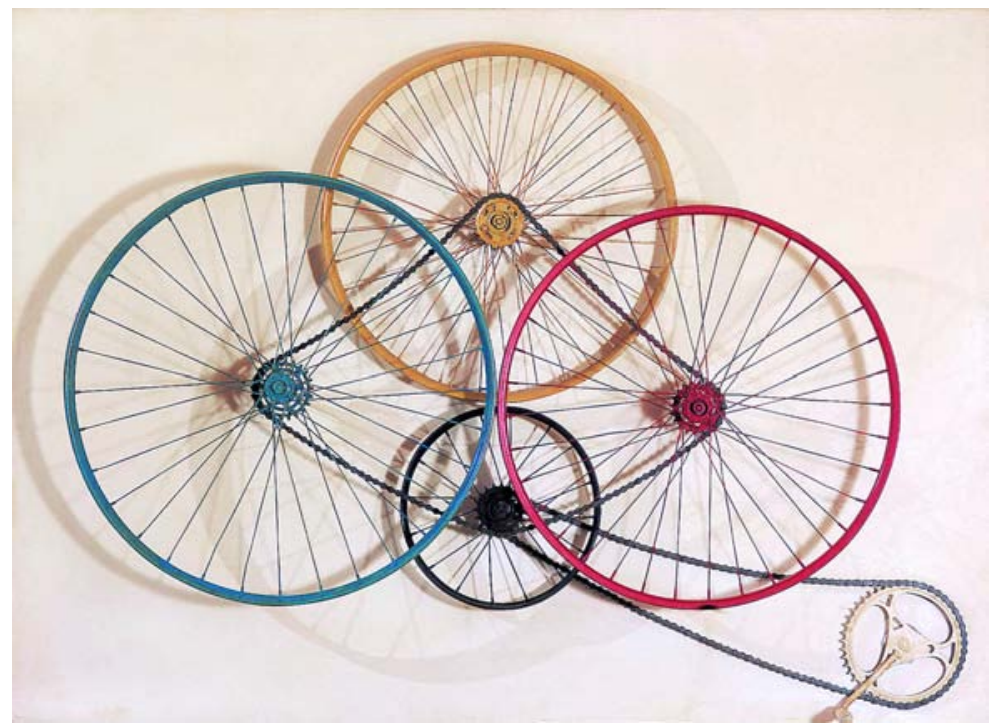


Figura 9: Pirambu, 1973

(com Nelson Machado e Raul Dada / Unicamp)

plotagem, $25.5 \times 37.5 \mathrm{~cm}$

Acervo Família Cordeiro

Foto: Acervo Família Cordeiro

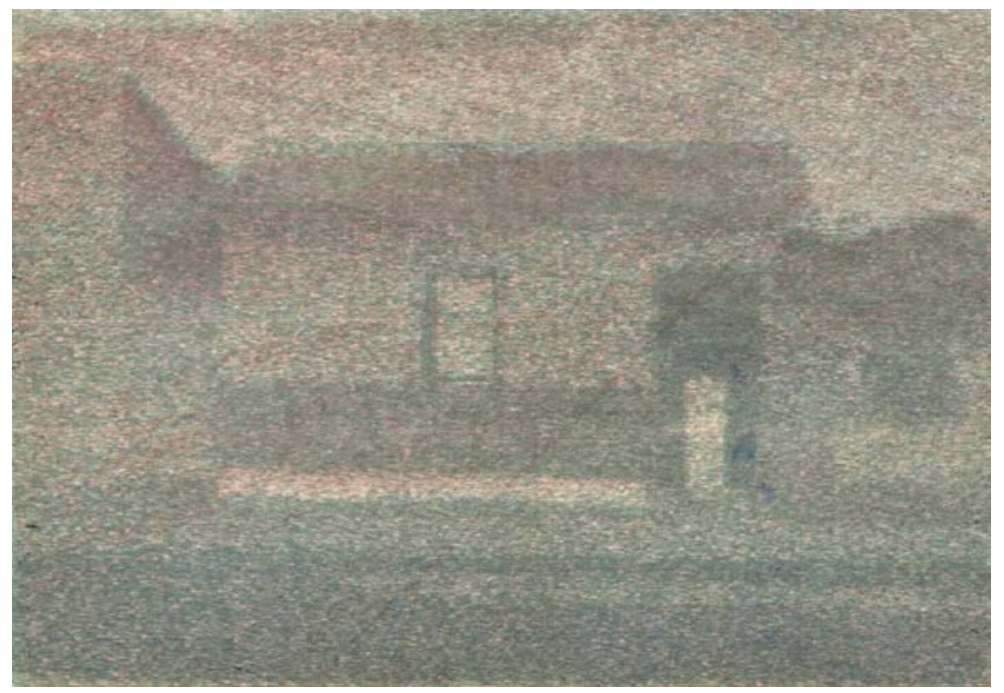

